\title{
A quantitative method for measuring the transfection efficiency of CD19-directed chimeric antigen receptor in target cells
}

\author{
Na Fang ${ }^{B, C}$, Niannian Zhong ${ }^{C}$, Tingxuan $\mathrm{Gu}^{\mathrm{B}}$, Yahui Wang ${ }^{\mathrm{B}}$, Xiangqian Guo ${ }^{\mathrm{E}}$, Shaoping Ji ${ }^{\mathrm{A}, \mathrm{D}, \mathrm{F}}$ \\ Department of Biochemistry and Molecular Biology, Medical School, Henan University, Kaifeng, China \\ A - research concept and design; $B$ - collection and/or assembly of data; $C$ - data analysis and interpretation; \\ $D$ - writing the article; $E$ - critical revision of the article; $F$ - final approval of the article
}

\section{Address for correspondence}

Shaoping Ji

E-mail: shaopingji@henu.edu.cn

\section{Funding sources}

National Natural Science Foundation of China (No. 31371386); Program for Excellent Talents in Henan Province (No. 124200510010); Program for Researchers in the Educational System in Henan Province (No.17A310004).

\section{Conflict of interest}

None declared

Received on January 6, 2017

Reviewed on February 17, 2017

Accepted on May 5, 2018

Published online on December 5, 2018

\begin{abstract}
Background. Adoptive cell therapy (ACT) based on chimeric antigen receptors (CARs) expressed on the surface of T cells shows a remarkable clinical outcome, particularly for B-cell malignancies. However, toxicity and side effects of CD19-redirected CART cells have been observed concurrently in most cases due to cytokine release and tumor cell lysis. Therefore, strictly controlling the amount of valid $\mathrm{T}$ cells re-transfused to patients seems to be an important step in reducing toxicity and side effects of CART cells. Transfection efficiency via lentiviral particles varies widely in different cases.
\end{abstract}

Objectives. The aim of this study was to accurately calculate and control the number of valid CAR T cells through ACT because the restriction antibiotics gene or the fluorescence gene are not suitable for tracking or screening for valid transfected $\mathrm{T}$ cells.

Material and methods. We expressed and purified a GFP-CD19 fusion protein as a probe to measure the expression efficiency of CD19-redirected CAR on the cell surface in adherent and suspension cell lines.

Results. We can precisely calculate the transfected efficiency of lentiviral particles by counting the number of GFP-labeled cells under a microscope, as well as calculate the percentage by comparing the number of GFP-labeled cells to total cells.

Conclusions. We propose a method to control the number of valid cells in ACT and to reduce toxicity and side effects in clinical use - a convenient technique for monitoring the dosage of CAR T cells for patients.

Key words: immunotherapy, CAR-T, CD19, examination, B-cell malignancy

Cite as

Fang N, Zhong N, Gu T, Wang Y, Guo X, Ji S.

A quantitative method for measuring the transfection efficiency of CD19-directed chimeric antigen receptor in target cells. Adv Clin Exp Med. 2019;28(2):159-164. doi:10.17219/acem/90772

DOI

10.17219/acem/90772

Copyright

Copyright by Author(s)

This is an article distributed under the terms of the

Creative Commons Attribution Non-Commercial License

(http://creativecommons.org/licenses/by-nc-nd/4.0/) 


\section{Introduction}

Chimeric antigen receptors (CARs) were engineered by Gross et al., ${ }^{1}$ who first generated and expressed the chimeric T-cell receptor (TCR), which is composed of the TCR constant domains and variable domains of the antibody, and these chimeric genes are non-MHC-restricted. A specific single chain fragment variable (scFv) from anti-tumorassociated antigen (TAA) antibody was fused to T-cell activation-related domains and was expressed on membrane of the cells. ${ }^{2}$ As a result, the T cells display tumor-targeted cytotoxic activity and the ability to proliferate sustainably. Subsequently, a CD19-redirected CAR T cell targeted against B-cell malignancies was developed and clinically tested, and it demonstrated remarkable effectiveness both in children and adult patients. ${ }^{3,4}$ Chimeric antigen receptor T-cell therapy provides a novel treatment choice for blood cancer patients, particularly for relapsed and refractory leukemia.

CD19 is a specifically expressed antigen in the B lymphocyte lineage, maintaining an upregulated expression during the early B-lineage cells to the mature B cell differentiation until final downregulation during terminal differentiation cells, and that CD19 has become a chimeric immunotarget for malignant B cells, including acute lymphoblastic leukemia (ALL) and non-Hodgkin's lymphomas (NHL). ${ }^{5}$ In addition, another publication revealed an essential role for CD19 in promoting early B-cell activation events in response to membrane-bound ligand stimulation. ${ }^{6}$ Therefore, CD19 chimeric antigen receptor therapy in oncology has progressed remarkably in recent years, especially for refractory/relapsed hematological malignancies. $^{3,4,7-9}$ Furthermore, a recently modified CAR based on cancer-associated Tn-Glycoform has revealed the effect of CAR T cells on solid cancer. ${ }^{10}$ In clinical studies, $\mathrm{T}$ cells were collected from a patient with leukapheresis and then isolated and activated with antibodies ${ }^{11}$ which induced $T$ cell activation and proliferation, thereby making the cells more likely to be responsible for viral transduction. These transduced cells can be expanded to the required quantity. Quality control and assurance assays are necessary before the prepared $\mathrm{T}$ cells can be re-transfused to patients. ${ }^{12}$

However, there are many challenges and considerations. For instance, if the dose of infused CAR T cells is insufficient, the expected result may not be achieved; on the other hand, an over-infused dose may cause toxicities mediated by CAR T cells, such as cytokine release syndrome (CRS). ${ }^{13}$ An effective method for examining and quantifying the transduced cells could help to accurately control the amount of infused CAR T cells administered to the patient, and could therefore lead to a more effective treatment. Flow cytometry (FCM) is a good choice, but a new set of detection apparatus must be used for each individual patient to protect against cross-infection. The cost of the FCM detection method can be prohibitive.
Green/red fluorescent protein (GFP) has been a useful tool for intracellular study since it was discovered ${ }^{14}$ and it is used as a marker for gene expression. ${ }^{15}$ These noninvasive and visualization proteins can serve as a marker for quantifying the number of interest infected $\mathrm{T}$ cells when administered clinically ${ }^{16}$ or can be used to determine the ratio of infected cells to total cells. In addition, an antibiotic-resistance gene used in a recombinant vector is another method of screening for infected cells or valid cells with removing the uninfected cells. However, both approaches have employed exotic genes/proteins which are immunogenic molecules and pose a potential hazard to patients in clinical use. In this study, we fused GFP to CD19 as a fusion protein, expressed it in Escherichia coli and purified it as a probe, so as to examine the infection efficiency of the CD19-directed chimeric antigen receptor on the surface of $\mathrm{T}$ cells based antigen-antibody interactions. Positive cells are marked with the GFP-CD19 fusion protein, due to the CD19-directed CAR being expressed on the surface of the infected cells. Valid CAR T cells can be calculated by counting the number of positive cells. Using this method, the number of valid cells can be accurately calculated before being re-transfused to patients.

\section{Material and methods}

\section{Cloning of target genes}

The CD19 gene and the GFP gene were amplified with polymerase chain reaction (PCR) from cDNA (GeneChem, Shanghai, China) and pET-28b-EGFP plasmid (Dingguo Changsheng, Beijing, China), respectively. The specific DNA primers for CD19 with restriction sites BamHI (upstream) and HindIII (TaKaRa, Osaka, Japan) (downstream) were 5'- AGGATCCGAGGAACCTCTAGTGGTGAAGG-3' (up) and 5'- CAAGCTTTCACCTGGTGCTCCAGGTGCCC-3' (down). The specific DNA primers for GFP were 5'- GCATATGGTGAGCAAGGGCGAGGAG-3' (up) and 5'AGGATCCCTTGTACAGCTCGTCCATGCC-3' (down) with restriction sites NdeI and BamHI (TaKaRa) upstream and downstream, respectively. The PCR products were analyzed in $1.0 \%$ agarose gel and purified.

\section{Plasmid construction}

The target DNA was isolated through electrophoresis in $1.0 \%$ agarose gel. In brief, the gels with DNA fragments were excised and purified with a Gel Extraction Kit (Lifefeng, Shanghai, China). These fragments were inserted into pGEM T-Easy plasmid (Promega, Madison, USA) using T/A cloning. The ligation products were transformed into Top10 competent $E$. coli cells. Following a heat shock, the transformed cells were recovered in super optimal broth with catabolite repression (super optimal catabolite repression (SOC) medium, $2 \%$ tryptone, $0.5 \%$ yeast extract, 
$0.05 \%$ sodium chloride $(\mathrm{NaCl}), 2.5 \mathrm{mM}$ potassium chloride $(\mathrm{KCl}), 10 \mathrm{mM}$ magnesium chloride $\left(\mathrm{MgCl}_{2}\right)$, and $20 \mathrm{mM}$ glucose) at $37^{\circ} \mathrm{C}$ for $45 \mathrm{~min}$. Recombinant colonies were cultured in agar plates ( $1 \%$ tryptone, $0.5 \%$ yeast extract, $1 \% \mathrm{NaCl}$, and $1.5 \%$ agar). Notably, the ligation product should be incubated at $70^{\circ} \mathrm{C}$ for 5 min to inactivate the ligase before the transformation. The recombinant plasmids were extracted from the bacteria and identified using endonuclease analysis. The CD19-T vector recombinant plasmid was identified by BamHI and HindIII, and the GFP-T vector by NdeI and BamHI. The inserted sequences were verified through DNA sequencing (Sangon Biotech, Shanghai, China).

Subsequently, the verified CD19-T vector recombinant plasmid and pCold TF plasmid which contained CspA promoter (a cold promoter, used to induce expression at low temperatures) and an ampicillin-resistance gene were digested by BamHI and HindIII, respectively. Electrophoresis with $1.0 \%$ agarose gel was performed. The target CD19 gene fragment and the linearized pCold TF plasmid in the gels were purified and ligated with T4 DNA ligase. The ligation products were transformed into Top10 competent E. coli cells, which were then cultured in agar plates and SOC medium with ampicillin. The reconstructed CD19-pCold TF plasmid was extracted from the bacteria and identified by BamHI and HindIII. Finally, the GFP-T vector recombinant plasmid and this CD19-pCold TF plasmid were digested by NdeI and BamHI, respectively. The GFP gene fragment and CD19-pCold TF plasmid vector were purified and the GFP-CD19-pCold TF recombinant plasmid was constructed through ligation and identified with NdeI and HindIII.

\section{Construction of CD19-CAR lentiviral vector and packaging of lentivirus}

The CD19-CAR lentiviral expression plasmid was constructed and the insert included the Kozak sequence, the IL-2 signaling peptide, scFv antibody, Fc hinge, CD28 transmembrane domain, 4-1 BB signaling domain, and CD3 zeta. The scFv antibody fragment is a gift from our colleague Dr. Jianghai Liu (Sichuan University, Chengdu, China), and the rest of the insert was a gift from Dr. Guo's lab (University of Saskatchewan, Saskatoon, Canada). The whole insert was inserted into lentiviral expression vector $\mathrm{PCDH}$-EF1 (no fluorescence). The recombinant vector was identified with $\mathrm{XbaI}$ and SalI and verified through sequencing. The lentiviral particles were purchased from Shanghai GenePharma Co. Ltd (Shanghai, China). The final virus titer was $1 \times 10^{8} \mathrm{TU} / \mathrm{mL}$.

\section{Protein GFP-CD19 expression}

The GFP-CD19-pCold TF recombinant plasmid was transformed into BL21(DE3) competent E. coli bacteria for expression. ${ }^{17}$ After overnight incubation in agar plates, single colonies were picked from the plates and placed into lysogeny (LB) broth with ampicillin to grow overnight at $37^{\circ} \mathrm{C}$ in a shaker.

This cultured medium was transferred into fresh LB (1:200) with ampicillin in a flask to culture for about $2 \mathrm{~h}$ until its OD 600 value was 0.5 . The culture was cooled at room temperature. When the temperature of the broth dropped to $15^{\circ} \mathrm{C}$, isopropyl- $\beta$-D-thiogalactopyranoside (IPTG; Solarbio, Beijing, China) was added into the culture. The final concentration of IPTG in the culture was $0.5 \mathrm{mM}$ and the bacteria were cultured at $15^{\circ} \mathrm{C}$ for additional $4 \mathrm{~h}$. Cells were harvested using centrifugation at $4000 \mathrm{~g}$ at room temperature for $10 \mathrm{~min}$ and they appeared to be green under visible light. The harvested cells were stored at $-80^{\circ} \mathrm{C}$ or used immediately.

\section{Protein purification}

The cell pellet harvested from $100 \mathrm{~mL}$ of the culture described above was re-suspended in $25 \mathrm{~mL}$ of phosphatebuffered saline (PBS; $137 \mathrm{mM} \mathrm{NaCl}, 2.7 \mathrm{mM} \mathrm{KCl,} 10 \mathrm{mM}$ disodium phosphate $\left(\mathrm{Na}_{2} \mathrm{HPO}_{4}\right)$ and $2 \mathrm{mM}$ monopotassium phosphate $\left(\mathrm{KH}_{2} \mathrm{PO}_{4}\right.$ at a $\mathrm{pH}$ of 7.0$)$ with $1 \mathrm{mM}$ of phenylmethylsulfonyl fluoride (PMSF) and 0.5\% Triton X-100 $(0.5 \%)$ on ice. The sample was frozen at $-80^{\circ} \mathrm{C}$ for $30 \mathrm{~min}$ and were taken out. After thawing out, it was sonicated at $85 \mathrm{~W}$ for $6 \mathrm{~s}$, followed by $7 \mathrm{~s}$ on ice in order to shear the DNA for lower viscosity. Sonication and icing were repeated 5-7 times in all samples until the solution was clear. The cell debris was centrifuged at $12,000 \mathrm{~g}$ for $10 \mathrm{~min}$ at $4^{\circ} \mathrm{C}$. The supernatant was then transferred to a new tube. Then, sodium dodecyl sulfate-polyacrylamide gel electrophoresis (SDS-PAGE) for the supernatant was performed to figure out the solubility of the protein. The rest of the supernatant was stored at $-20^{\circ} \mathrm{C}$ or on ice for the following step.

Ni-NTA-agarose purification was prepared and $4 \mathrm{~mL}$ of Ni-NTA resin (beads) was pipetted into a $10 \mathrm{~mL}$ purification column. The resin was washed using 5 column volume $(\mathrm{CV})$ of deionized water and then $5 \mathrm{CV}$ of PBS (pH 7.0) for equilibrium. Twenty-five milliliters of the supernatant was slowly added into the column for binding. The protein in the column was washed with $5 \mathrm{CV}$ of $\mathrm{PBS}$ (pH 7.0) and $3 \mathrm{CV}$ of wash buffer (PBS pH 7.0 buffer containing 20mM imidazole) successively, and eluted with PBS (pH 7.0) with 250mM of imidazole into a new tube. The resin was again washed with PBS (pH 7.0) with $800 \mathrm{mM}$ of imidazole (3 CV). Finally, the column was washed with PBS (pH 7.0) 5-8 times, with sterile deionized water 3-5 times and washed again with $20 \mathrm{~mL}$ of $20 \%$ ethanol; then it was filled with $20 \%$ alcohol and stored at $4{ }^{\circ} \mathrm{C}$. The eluted protein was confirmed using SDS-PAGE analysis. The $250 \mathrm{mM}$ of imidazole was centrifuged at 4,500 $\mathrm{g}$ for $50 \mathrm{~min}$ at $4^{\circ} \mathrm{C}$ in an ultrafiltration centrifuge tube (Merck Millipore, Billerica, USA), in order to remove small molecular substances and to concentrate the purified protein. This step was repeated and the protein was concentrated to $2.0 \mu \mathrm{g} / \mathrm{mL}$. 


\section{Infection of 3 cell lines}

The lentiviral vector was packaged for CD19-CAR expression and the titer was $1 \times 10^{8} \mathrm{TU} / \mathrm{mL}$ (GenePharma). First, the HEK 293 cells $\left(5 \times 10^{4} / \mathrm{mL}\right)$ were seeded in 6 of the wells ( $500 \mu \mathrm{L}$ each) of a 24 -well plate. After the seeded cells were cultured for $12 \mathrm{~h}$, the media were replaced with infection mix. Three of the wells had $490 \mu \mathrm{L}$ of complete medium, $10 \mu \mathrm{L}$ of lentivirus and $0.5 \mu \mathrm{L}$ of polybrene added, with a working concentration of $5 \mu \mathrm{g} / \mathrm{mL}$ for each one. The other 3 control wells had only $500 \mu \mathrm{L}$ of complete medium added. Daudi cells and Jurkat cells were infected through the same process as the HEK 293 cells, but the method of treating the cells was different. The cells were cultured at $37^{\circ} \mathrm{C}$ in $5 \% \mathrm{CO}_{2}$ for $72 \mathrm{~h}$. Then, $5 \mu \mathrm{L}$ of the GFP-CD19 fusion protein was added to each culture $(0.2-2.0 \mu \mathrm{g} / \mathrm{mL})$. Subsequently, the cells were cultured under the same conditions for another $6 \mathrm{~h}$, the media were replaced by PBS and the cells were observed with fluorescence microscope and quantified using cell counting in each chamber.

\section{Results}

\section{Plasmid construction}

The CD19 gene (coding sequence; $1671 \mathrm{bp}$ ) and the GFP gene (717bp) were acquired through PCR from commercial cDNA and pET28b-GFP plasmid, respectively, and were identified with $1 \%$ agarose gel electrophoresis, as shown in Fig. 1. Then, the target genes were ligated into $\mathrm{T}$ vector. The CD19 gene was identified by BamHI and HindIII. A 1671bp fragment can be seen in Fig. 2A. Similarly, the GFP gene was identified by NdeI and BamHI. A 717bp gene fragment shows correctly in Fig. 2B. Furthermore, the sequencing results of the constructed $\mathrm{T}$ vector plasmids were also correct. The CD19 gene was cut and then ligated to pCold TF vector. The recombinant plasmid was identified by BamHI
A

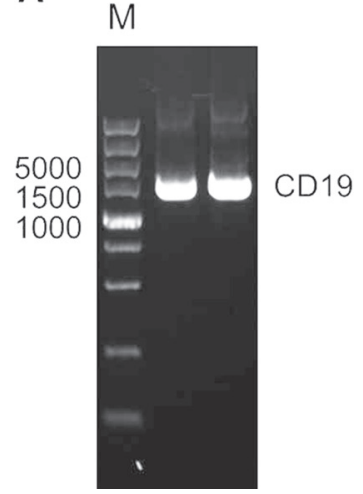

B

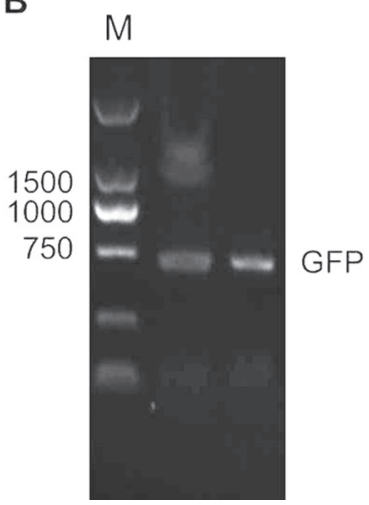

Fig. 1. Polymerase chain reaction (PCR) results of CD19. The 2 lanes are the CD19 encoding region (A); the GFP gene (B) is amplified as shown in both lanes
A

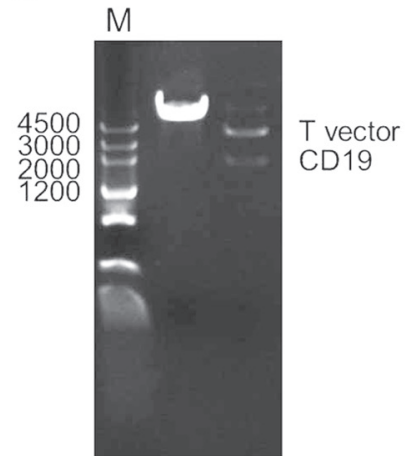

M

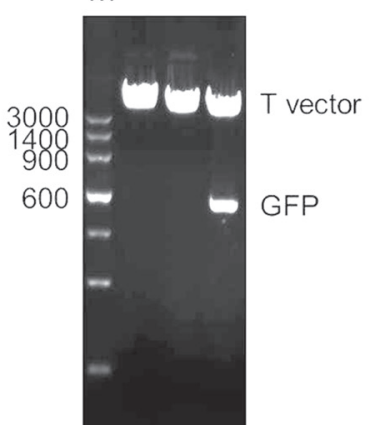

Fig. 2. Identification of the CD19-T vector plasmid (A) through digestion with EcoRl in the right lane. The GFP-T vector plasmid (B) was identified with EcoRI and the right lane is a positive clone. Both vectors were verified with sequencing

A

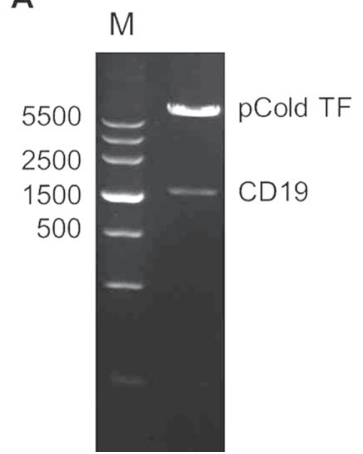

B

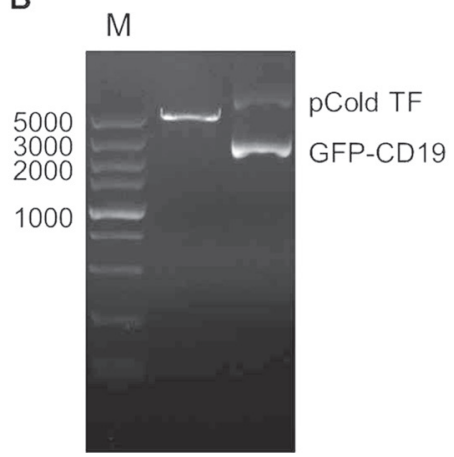

Fig. 3. Identification of the recombinant plasmids CD19-pCold TF (A) and CD19-GFP-pCold TF (B). Correct bands were cut out from both recombinant vectors, indicating that the vectors are correct

and HindIII. A 1671bp gene fragment and a 5769bp gene fragment can be seen in Fig. 3A. The GFP gene was ligated to this recombinant plasmid and identified by NdeI and BamHI. The 2388bp gene fragment of the CD19-GFP gene and a 5769bp gene fragment of linearized pCold TF plasmid visible in Fig. 3B indicate that the recombinant plasmid was constructed successfully.

\section{Expression and purification of the CD19-GFP fusion protein}

The CD19-GFP fusion protein induced by IPTG was expressed in BL21 E. coli bacteria and collected. It was purified using Ni-NTA-agarose purification and concentrated using protein concentrators. The expression and purification results were confirmed using SDS-PAGE (Fig. 4).

\section{Quantitative analysis of infected efficiency}

The CD19-CAR was transduced by lentiviral vector into HEK 293 cells. There was no green or red fluorescence particles visible in the cells which were infected by the lentivirus. Expression of GFP can be detected under a microscope due to the specificity of CAR T cells. The images captured 


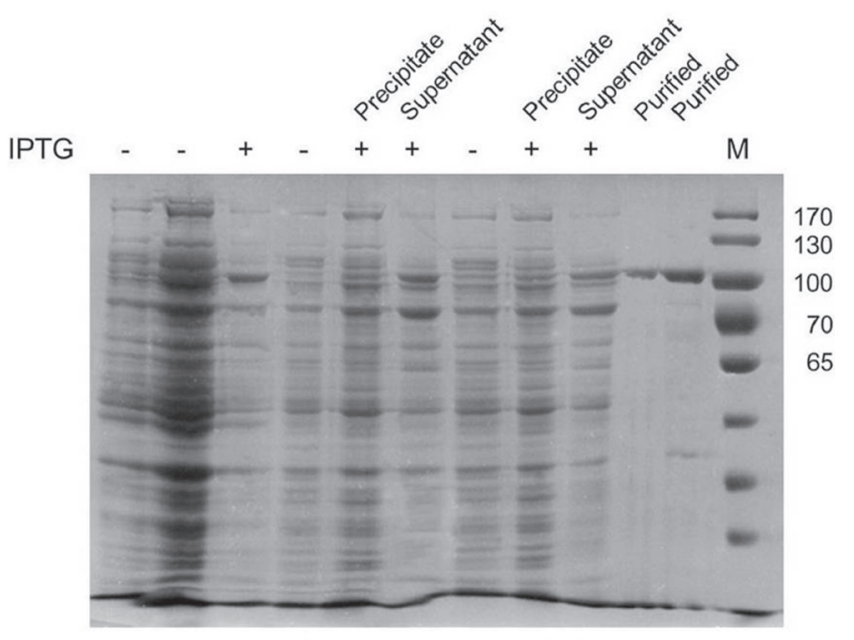

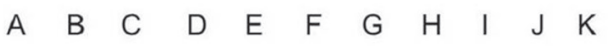

Fig. 4. Expression and purification of the CD19-GFP fusion protein ( $, B, D$, and $\mathrm{G})$; protein expression of bacteria before IPTG induction (C); protein expression of bacteria after IPTG induction ( $E$ and $\mathrm{H})$; the precipitate of protein expression of the bacteria after IPTG induction ( $F$ and I); the supernatant of protein expression of bacteria after IPTG induction ( $\mathrm{J}$ and $\mathrm{K}$ ); the target protein purified using the Ni-NTA-agarose purification system

under a fluorescent microscope and shown in Fig. 5 prove that the fusion proteins were targeted to HEK 293 cells, Daudi cells and Jurkat cells. Moreover, the expression rate of CAR in transduced Daudi cells was $42 \%$ while it was $76 \%$ in the Jurkat cells.

\section{Discussion}

CD19 mainly expresses on B-lineage cells, which makes it a specific antigen for immunotherapy ${ }^{18}$ CD19-directed CAR T cells against B-cell malignancies provides a novel and effective treatment for patients, particularly for those with relapsed and refractory B-lineage leukemia. ${ }^{19-22}$ Except engineered T cell, CD19-redirected NK92 cells also show a promising result against B-lineage leukemia. ${ }^{23}$ In addition, CD19-redirected $\mathrm{T}$ memory stem cells represent a potential method for the treatment of $\mathrm{B}$-lineage leukemia. ${ }^{24}$ In the process of engineering therapeutic cells, another vector, apart from the lentiviral vector, is also employed to mediate the expression of CAR. ${ }^{25}$

Toxicity and the side effects of CD19-directed CAR $\mathrm{T}$ cells are increasingly drawing attention to this immunotherapy. The main mechanism of the toxicity and side effects could be attributed to cytokine release, tumor cell lysis, B-cell aplasia, and macrophage-activation syndrome. ${ }^{26,27}$ Although most mild toxicity and side effects are reversible, some severe toxicities need medical treatment. A low dose of engineered cells may not trigger a response of antitumor activity, and an extra dose of immunotherapeutic cells may lead to severe toxicity and side effects. Therefore, administering the appropriate amount of engineered $\mathrm{T}$ cells to patients may be the first step in controlling the occurrence of toxicity and side effects.
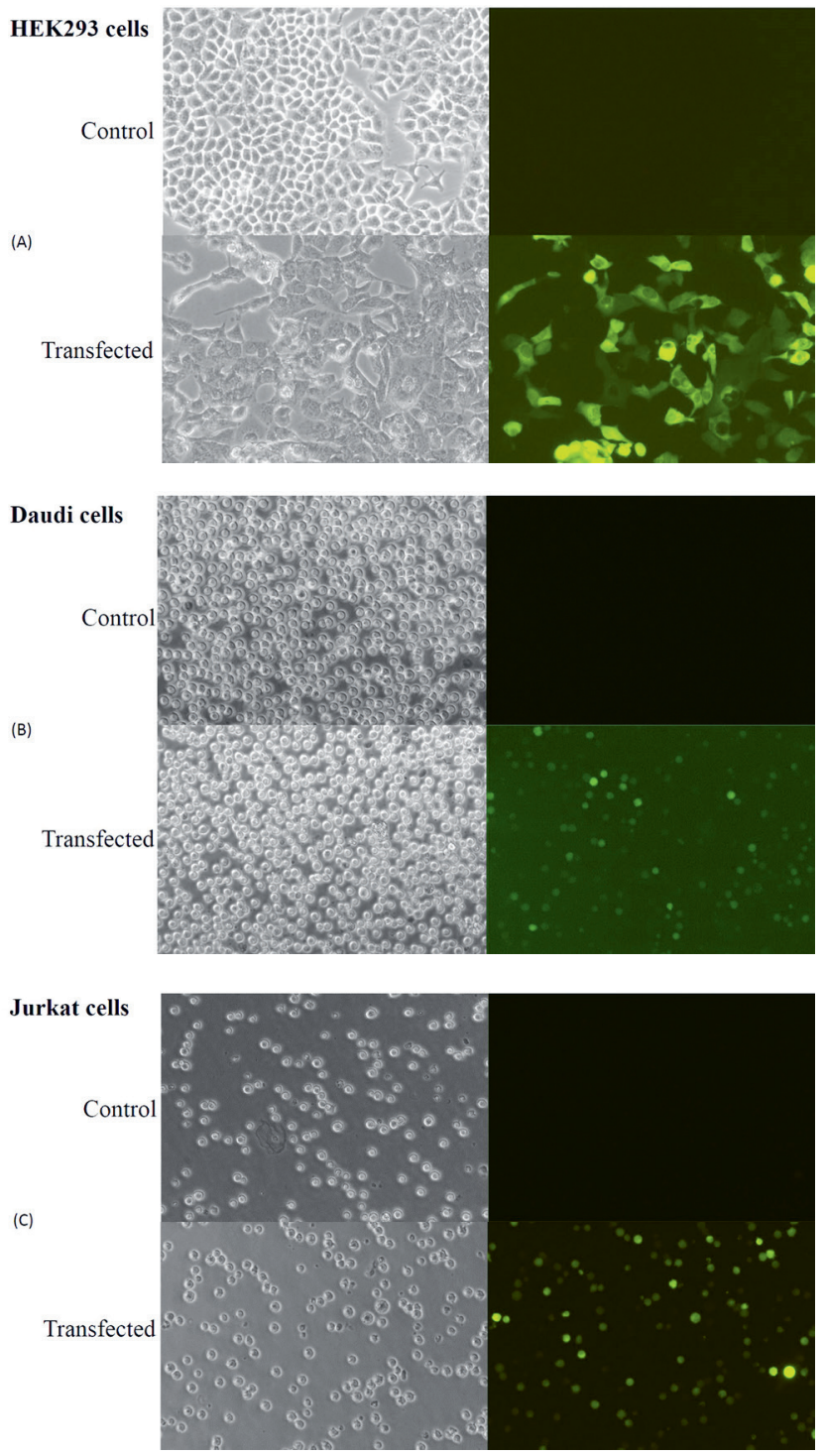

Fig. 5. GFP-expressing cells under a microscope ( $\times 100$ magnification). Bright field images and cell fluorescence images of HEK 293 cells. Control - HEK 293 cells without infection (A). Bright field images and cell fluorescence images of Daudi cells. Control - Daudi cells without infection (B). Bright field images and cell fluorescence images of Jurkat cells. Control - Jurkat cells without infection (C)

It is widely accepted that a correct dosage of CAR $\mathrm{T}$ cells is required for each re-transfusion to patients, ${ }^{12,19}$ so the infection efficiency and the number of valid CAR $T$ cells is accurately calculated before re-transfusion. Due to the alteration of infection efficiency, valid CAR T cells cannot be estimated from the total number of infused cells. In order to track infection efficiency or to screen for valid infected cells by removing uninfected cells, a fluorescence protein gene and a resistant gene are commonly used in molecular manipulation. Valid cells can be counted and calculated before re-transfusion by the former method, and valid cells can be gathered by removing uninfected cells via the latter one. Both methods can provide us with an approach using which we can accurately control the infusion dosage of CAR T cells rather than the number of total cultured cells. 
Unfortunately, both proteins are derived from exotic genes and their products carry immunogenicity to acceptors, ${ }^{28}$ leading to impairment when these proteins are infused into patients along with CAR T cells. On the other hand, if flow cytometry is employed with an immunofluorescence antibody, it will increase the cost of treatment because each sorting process requires a new set of sorting apparatus. In addition, the application of an immunofluorescence antibody may become a new immunogen, leading to new barriers in the application.

A safe and simple approach is needed in order to quickly determine the infection efficiency and to calculate the number of valid engineered cells in the application. In this study, we fused CD19 to GFP and expressed it in E. coli under a regular molecular biological process. The fusion protein solubility was optimized at $15^{\circ} \mathrm{C}$ and was purified with Ni-NTA agarose beads. ${ }^{29}$ After the target cells (including adherent and suspension cell lines) were infected with lentiviral particles, the purified fusion protein was directly added to the culture medium and left to culture for $6 \mathrm{~h}$. GFP could be directly observed under a microscope and the infected cells (expressing CD-19 CAR) could be determined from other cells (data not shown). The results would become clearer than before when the cultured medium (including CD19-GFP) was removed by washing the cells with a regular culture medium.

Because CD19-GFP (as an antigen) can be recognized by CAR expressed on the surface of the target cells, the fusion protein serves as a probe to visualize the CARexpressing cells. The non-specific binding of CD19-GFP to other proteins is negligible when a fluorescence microscope is used. The ratio of fluorescence cells to total cells can be calculated by determining the number of cells in fluorescence fractions and the number of total cells. In clinical use, the number of valid cells can be accurately administrated to patients. This method provides a novel approach to administrating a dose of CAR T cells in clinical practice using vectors free of the antibiotic-resistance gene and the fluorescence protein gene.

\section{References}

1. Gross G, Waks T, Eshhar Z. Expression of immunoglobulin-T-cell receptor chimeric molecules as functional receptors with antibodytype specificity. Proc Natl Acad Sci U S A. 1989;86(24):10024-10028.

2. Huston JS, Levinson D, Mudgett-Hunter M, et al. Protein engineering of antibody binding sites: Recovery of specific activity in an antidigoxin single-chain Fv analogue produced in Escherichia coli. Proc Natl Acad Sci U S A. 1988;85(16):5879-5883.

3. Porter DL, Levine BL, Kalos M, Bagg A, June $\mathrm{CH}$. Chimeric antigen receptor-modified T cells in chronic lymphoid leukemia. NEnglJMed. 2011;365(8):725-733.

4. Grupp SA, Kalos M, Barrett D, et al. Chimeric antigen receptor-modified T cells for acute lymphoid leukemia. N Eng/ J Med. 2013;368(16): 1509-1518.

5. Scheuermann RH, Racila E. CD19 antigen in leukemia and lymphoma diagnosis and immunotherapy. Leuk Lymphoma. 1995;18(5-6):385-397.

6. Depoil D, Fleire S, Treanor BL, et al. CD19 is essential for B cell activation by promoting $B$ cell receptor-antigen microcluster formation in response to membrane-bound ligand. Nat Immunol. 2008; 9(1):63-72.
7. Brentjens RJ, Davila ML, Riviere I, et al. CD19-targeted T cells rapidly induce molecular remissions in adults with chemotherapy-refractory acute lymphoblastic leukemia. Sci Trans/Med. 2013;5(177):177ra38.

8. Kalos $\mathrm{M}$, Levine BL, Porter $\mathrm{DL}$, et al. T cells with chimeric antigen receptors have potent antitumor effects and can establish memory in patients with advanced leukemia. Sci Trans/Med. 2011;3(95):95ra73.

9. Kochenderfer JN, Wilson WH, Janik JE, et al. Eradication of B-lineage cells and regression of lymphoma in a patient treated with autologous T cells genetically engineered to recognize CD19. Blood. 2010;116(20):4099-4102.

10. Posey AD Jr, Schwab RD, Boesteanu AC, et al. Engineered CAR T cells targeting the cancer-associated Tn-glycoform of the membrane mucin MUC1 control adenocarcinoma. Immunity. 2016;44(6):1444-1454.

11. Wang X, Riviere I. Manufacture of tumor- and virus-specific Tlymphocytes for adoptive cell therapies. Cancer Gene Ther. 2015;22(2):85-94.

12. Davila ML, Sadelain M. Biology and clinical application of CART cells for B cell malignancies. Int J Hematol. 2016;104(1):6-17.

13. Kochenderfer JN, Dudley ME, Feldman SA, et al. B-cell depletion and remissions of malignancy along with cytokine-associated toxicity in a clinical trial of anti-CD19 chimeric-antigen-receptor-transduced T cells. Blood. 2012;119(12):2709-2720.

14. Johnson FH, Shimomura O, Saiga Y. Action of cyanide on Cypridina luciferin. J Cell Comp Physiol. 1962;59:265-272.

15. Chalfie M, Tu Y, Euskirchen G, Ward WW, Prasher DC. Green fluorescent protein as a marker for gene expression. Science. 1994;263(5148): 802-805.

16. Arun KH, Kaul CL, Ramarao P. Green fluorescent proteins in receptor research: An emerging tool for drug discovery. J Pharmacol Toxicol Methods. 2005;51(1):1-23.

17. Subedi GP, Satoh T, Hanashima $S$, et al. Overproduction of anti-Tn antibody MLS128 single-chain Fv fragment in Escherichia coli cytoplasm using a novel pCold-PDI vector. Protein Expr Purif. 2012;82(1):197-204.

18. Turtle CJ, Riddell SR, Maloney DG. CD19-Targeted chimeric antigen receptor-modified T-cell immunotherapy for B-cell malignancies. Clin Pharmacol Ther. 2016;100(3):252-258.

19. Onea AS, Jazirehi AR. CD19 chimeric antigen receptor (CD19 (AR)-redirected adoptive T-cell immunotherapy for the treatment of relapsed or refractory B-cell Non-Hodgkin's Lymphomas. Am J Cancer Res. 2016;6(2):403-424.

20. Sadelain M, Brentjens R, Riviere I, Park J. CD19 CAR therapy for acute lymphoblastic leukemia. Am Soc Clin Oncol Educ Book. 2015:e360-363.

21. Sadelain M. CAR therapy: The CD19 paradigm. J Clin Invest. 2015;125(9): 3392-3400.

22. Miller BC, Maus MV. CD19-targeted CART cells: A new tool in the fight against B cell malignancies. Oncol Res Treat. 2015;38(12):683-690.

23. Romanski A, Uherek C, Bug G, et al. CD19-CAR engineered NK-92 cells are sufficient to overcome NK cell resistance in B-cell malignancies. J Cell Mol Med. 2016;20(7):1287-1294.

24. Sabatino M, Hu J, Sommariva M, et al. Generation of clinical-grade CD19-specific CAR-modified CD8 ${ }^{+}$memory stem cells for the treatment of human B-cell malignancies. Blood. 2016;128(4):519-528.

25. Kebriaei $P$, Singh $H$, Huls $M H$, et al. Phase I trials using Sleeping Beauty to generate CD19-specific CAR T cells. J Clin Invest. 2016;126(9): 3363-3376.

26. Ruella M, Barrett DM, Kenderian SS, et al. Dual CD19 and CD123 targeting prevents antigen-loss relapses after CD19-directed immunotherapies. J Clin Invest. 2016;126(10):3814-3826.

27. Wang L, Ma N, Okamoto S, et al. Efficient tumor regression by adoptively transferred CEA-specific CAR-T cells associated with symptoms of mild cytokine release syndrome. Oncoimmunology. 2016;5(9): e1211218.

28. Ansari AM, Ahmed AK, Matsangos AE, et al. Cellular GFP toxicity and immunogenicity: Potential confounders in in vivo cell tracking experiments. Stem Cell Rev. 2016;12(5):553-559.

29. Jawale CV, Lee JH. Development of a biosafety enhanced and immunogenic Salmonella enteritidis ghost using an antibiotic resistance gene free plasmid carrying a bacteriophage lysis system. PLoS One. 2013;8(10):e78193. 